\title{
Acta
Biochimica
Polonica
}

Vol. 48 No. $3 / 2001$

$647-656$

QUARTERLY

\section{Modification of non-protein thiols contents in transgenic tobacco plants producing bacterial enzymes of cysteine biosynthesis pathway ${ }^{\star \otimes}$}

\author{
Frantz Liszewska, Anna Błaszczyk and Agnieszka Sirko \\ Institute of Biochemistry and Biophysics, Polish Academy of Sciences, Warszawa, Poland
}

Received: 18 April, 2001; revised: 30 May, 2001; accepted: 3 August, 2001

Key words: cysteine biosynthesis, sulfur metabolism, thiols, transgenic tobacco

\begin{abstract}
Conditions of achieving the maximal accumulation of sulfhydryl metabolites in the leaves of tobacco were explored. Simultaneous production of bacterial $O$-acetylserine (thiol)-lyase and serine acetyltransferase resulted in the increased thiols contents as compared to single transformants and controls. However, leaf discs feeding experiments differently affected thiols concentration in different plant groups and suggested that the most promising strategy to obtain plants with a high level of non-protein thiol-containing compounds might be sulfate feeding to plants overproducing serine acetyltransferase.
\end{abstract}

Formation of cysteine from sulfide and $O$-acetyl-L-serine (OAS) is catalyzed by $O$-acetylserine (thiol)-lyase (OAS-TL) (EC 4.2.99.8) while OAS is synthesized by serine acetyltransferase (SAT) from acetyl-coenzyme A and serine. Molecular interactions between SAT and OAS-TL are involved in the regulation of the enzymatic activities of these proteins in bacteria (Mino et al., 2000) and in plants (Bogdanova \& Hell, 1997; Droux et al., 1998). Experiments with Escherichia coli enzymes clearly indicated that OAS-TL activity was reduced to $30 \%$ in a complex (Mino et al., 2000). Similarly, a very dramatic decrease of

\footnotetext{
* Results reported in this paper were presented as a poster at the 18th International Congress of Biochemistry and Molecular Biology, July 2000, Birmingham, U.K.

The Polish and French Ministries of Education are acknowledged for a scholarship to F.L. This work was supported in part by grant 6P04A04319 to A.B. from the State Committee for Scientific Research (KBN, Poland).

${ }^{\square}$ Corresponding author: Dr. A. Sirko, Institute of Biochemistry and Biophysics, Polish Academy of Sciences, A. Pawińskiego 5A, 02-106 Warszawa, Poland; tel.: (48 22) 658 4801; fax: (48 39) 121 623; e-mail: asirko@ibb.waw.pl
}

Abbreviations: DTNB, 5,5-dithio-2-nitrobenzoic acid; GSH, glutathione reduced; MES, 4-morpholine-ethanesulfonic acid; OAS, $O$-acetyl-L-serine; OAS-TL, $O$-acetylserine (thiol)-lyase; SAT, serine acetyltransferase. 
the catalytic activity of OAS-TL bound in a complex has been reported for the plant enzymes (Droux et al., 1998). On the other hand, the bienzyme complex formation stabilizes bacterial SAT (Mino et al., 2000) and increases the apparent affinity for the substrates of plant SAT (Droux et al., 1998). The stability of the complex is negatively affected by OAS and positively by sulfide (Droux et al., 1998). Bacterial SAT is feedback regulated by cysteine, however, no relationship seems to exist between the complex formation and SAT sensitivity to this inhibition (Mino et al., 2000).

Both enzymes, SAT and OAS-TL, are located in three compartments of the plant cell: the cytosol, chloroplasts and mitochondria. Different isoforms of these enzymes are in a different way regulated by sulfur nutrition (Nakamura et al., 1999; Takahashi et al., 1997; Warrilow \& Hawkesford, 1998). The feedback regulation by L-cysteine of various isoforms of plant SAT has recently been studied (Inoue $e t$ al., 1999; Noji et al., 1998). According to the model proposed, the only role of the chloroplastic and mitochondrial isoforms (that are insensitive to the feedback inhibition) would be the production of OAS for cysteine biosynthesis. The cysteine-sensitive cystosolic isoform of SAT would, according to this model, have two roles: (i) OAS production for cysteine biosynthesis in the cystosol and (ii) control of OAS pool for regulatory purposes. The second postulated function is tightly connected with the fact that OAS acts as a positive regulator of genes whose expression is affected by sulfur status (Saito, 2000).

Glutathione, the main low-molecular-mass thiol-containing compound in the plant cell, has multiple functions, including involvement in responses to various environmental stresses and maintenance of the redox homeostasis (Foyer \& Rennenberg, 2000). Under non-stressing conditions the majority of glutathione is maintained in the reduced form (GSH) and its concentration is determined mainly by the rate of biosynthesis. GSH is pro- duced from cysteine, glutamate and glycine in two steps catalyzed by $\gamma$-glutamylcysteinyl synthetase ( $\gamma$-ECS) and glutathione synthetase (GS), respectively (Noctor et al., 1998). The biosynthesis and accumulation of GSH has been shown to depend on (i) the activity of $\gamma$-ECS, (ii) the availability of cysteine, and (iii) the light-dependent formation of glycine through the photorespiratory pathway (Foyer \& Rennenberg, 2000).

The main aim of this study was to identify the optimal conditions for the maximal accumulation of non-protein sulfhydryl metabolites in plant leaves. The transgenic tobacco plants with cytosolic production of bacterial enzymes of the cysteine biosynthesis pathway, SAT and OAS-TL, were obtained and analyzed for the transgenes expression. Additionally, leaf discs of either single or double transformants, as well as of control plants, were assayed for the thiol contents upon incubation in solutions of various compounds expected to have an influence on sulfur metabolism.

\section{MATERIALS AND METHODS}

Plasmids construction. The cysK gene was amplified by PCR using genomic DNA of the EC1250 strain (Jagura-Burdzy \& Hulanicka, 1981) of Escherichia coli K-12 as a template and the following pair of primers: $5^{\prime}$-cgg gat cca tga agt aag att ttt gaa-3' and $5^{\prime}$-cgt tgt cat tac ggt cgc cat ggc g-3'. These primers introduced a BamHI site upstream of the translation start codon and a $K p n I$ site 7 nt behind the stop codon of cysK. The 1.0-kb PCR product was cloned after digestion with $\mathrm{BamHI}$ and KpnI into pUC19 (Yanisch-Perron et al., 1985). The SalI-KpnI insert from the resulting plasmid, pCK1, was then subcloned into pRTL2 (Carrington et al., 1991) digested with XhoI and KpnI, i.e. between the 35S promotor and terminator of cauliflower mosaic virus (CaMV). The $2.0 \mathrm{~kb}$ PstI-PstI DNA fragment with the cysK plant expression cassette was 
further recloned into binary vectors, either pGreen0029 or pGreen0229 (Hellens et al., 2000), in order to get plasmids pCK6 and pCK8 allowing selection of transgenic plants for kanamycin and phosphinotricin resistance, respectively.

Western blot analysis. Western blot analysis was performed according to the standard procedure (Sambrook et al., 1989). Rabbit anti-E. coli OAS-TL serum served as primary antibodies. Goat anti-rabbit IgGs conjugated with alkaline phosphatase were used as secondary antibodies. The immunoreactive proteins were visualized by a colorimetric method.

Plant material. Three lines of tobacco (Nicotiana tabacum) were used for the genetic transformations: the low alkaloid line LAB 21 (Legg et al., 1970), and transgenic lines producing E. coli SAT, CE-20 and CEM-12, which were the derivatives of the former one (Blaszczyk et al., 1999). The nomenclature of the transgenic plant lines obtained during this study (by genetic transformation of the three lines mentioned above) is explained in the $\mathrm{Re}-$ sults section.

Plant transformation. Tobacco seedlings were transformed according to the procedure described by Rossi et al. (1993) using overnight cultures of Agrobacterium tumefaciens (LBA4404) containing appropriate plasmids. Regenerating plantlets were cut out and relocated to plates with MS medium (Murashige \& Skoog, 1962) supplemented with vitamins and the appropriate selection markers (either 150 $\mathrm{mg} / \mathrm{l}$ kanamycin or both, $100 \mathrm{mg} / \mathrm{l} \mathrm{kanamycin}$ and $2.5 \mathrm{mg} / \mathrm{l} \mathrm{DL}$-phosphinothricin) to allow roots formation. Rooted plantlets were transferred to soil and checked for the presence of bacterial OAS-TL by Western analysis and enzyme assays. In the case of double transformants, the presence of the second insert was confirmed by the "leaf callus assay" (Firoozabady \& Kuehnle, 1995). Plant cultivation was continued in greenhouse conditions until seeds were collected.
Genetic analysis of transgenic plants. The seeds of self-pollinated primary transformants grown and flowered in a greenhouse were used for genetic analysis. Seeds were surface sterilized in a commercial bleach and germinated on MS medium containing either $150 \mathrm{mg} / \mathrm{l}$ kanamycin or $10 \mathrm{mg} / \mathrm{l}$ DL-phosphinothricin. Green vs. yellow seedlings were scored after 10 days in a growth chamber (photoperiod: $16 \mathrm{~h} \mathrm{light} / 8 \mathrm{~h}$ dark, $24^{\circ} \mathrm{C}$ ) and the segregation ratio was calculated.

OAS-TL assay. The selective-marker-resistant $\mathrm{T}_{1}$ seedlings germinated in vitro were transferred to the soil, cultivated for 5 weeks in a growth chamber (photoperiod: $16 \mathrm{~h}$ light $/ 8 \mathrm{~h}$ dark, $20^{\circ} \mathrm{C}$ ) and transferred to greenhouse conditions without additional light source (April/May). Plant material was collected from three successive leaves: the upper (most apical position, about 70\% developed), the middle (intermediate, fully developed) and the lower one (most basal position, mature). The material cut off at random from a leaf (about $100 \mathrm{mg}$ per sample) was collected in a microcentrifuge tube, kept on ice and ground using a micro-pestle after addition of $50 \mu \mathrm{l}$ of ice-cold $0.1 \mathrm{M}$ Tris/HCl, $\mathrm{pH}$ 7.6. The samples were centrifuged $\left(12500 \mathrm{~g}, 15 \mathrm{~min}, 4^{\circ} \mathrm{C}\right)$ and crude extracts were kept on ice until the enzymatic assays were performed (usually not longer than $60 \mathrm{~min}$ ). OAS-TL activity was determined according to the procedure described by Kredich \& Thomkins (1966). A unit of enzyme activity is defined as the amount of the enzyme that catalyzes the formation of 1 nmole L-cysteine per min under the conditions of the assay. Protein in the extracts was determined using a Protein Assay Kit (BioRad) and bovine serum albumine as a standard (Bradford, 1976).

SAT assay. The same crude extracts as for OAS-TL were assayed for SAT activity as previously described (Blaszczyk et al., 1999).

Incubation of leaf discs in various solutions and soluble thiols assay. Several leaf discs ( $8 \mathrm{~mm}$ in diameter) were cut out from 
the fourth well-developed leaf of plants cultivated in growth chamber conditions (photoperiod: $16 \mathrm{~h}$ light $/ 8 \mathrm{~h}$ dark, $20^{\circ} \mathrm{C}$ ). The leaf discs were transferred to Petrie dishes containing $20 \mathrm{ml}$ of aqueous solutions of compounds indicated in Fig. 4 that were buffered to $\mathrm{pH} 5.8$ with $1 \mathrm{mM}$ MES. Leaf discs were incubated for $45 \mathrm{~h}$ in the same growth chamber $\left(20^{\circ} \mathrm{C}\right)$ and the sequence of the light/dark conditions were as follows: $5 \mathrm{~h}$ light $/ 8 \mathrm{~h}$ dark/16 h light/8 h dark/8 h light. After time indicated the leaf discs were briefly washed in distilled $\mathrm{H}_{2} \mathrm{O}$, drained on filter paper and the soluble thiols contents in leaf samples was determined using 5,5-dithio-2-nitrobenzoic acid (DTNB). Leaf material (100 mg per sample) was frozen in liquid nitrogen, ground in a microcentrifuge tube and subsequently $400 \mu \mathrm{l}$ of ice-cold extraction solution $(1 \mathrm{~N} \mathrm{HCl}, 10$ mM EDTA) was added. After vortexing, the sample was centrifuged and supernatant collected for analysis. Aliquots $(180 \mu \mathrm{l})$ of the supernatants were added to a mixture containing $800 \mu \mathrm{l}$ of $0.5 \mathrm{M} \mathrm{Na}_{2} \mathrm{HPO}_{4}$ and $25 \mu \mathrm{l}$ of $10 \mathrm{mM}$ DTNB. The absorbance was immediately read at $412 \mathrm{~nm}$ and corrected for the absorbance of the mixture containing $25 \mu \mathrm{l}$ of distilled $\mathrm{H}_{2} \mathrm{O}$ instead of DTNB and the absorbance of DTNB itself. The amount of soluble reduced thiols was expressed as nmoles per gram of fresh mass.

\section{RESULTS}

Two binary plasmids, pCK6 and pCK8, containing a plant expression cassette with Escherichia coli cysK gene encoding OAS-TL enabled the selection of transgenic plants for kanamycin and phosphinotricin resistance, respectively. Before performing stable plant transformation, the functionality of both constructs was verified at the mRNA and protein levels by a transient in planta assay test (not shown). Subsequently, three lines of tobacco (Nicotiana tabacum) were used for Agrobacterium-mediated transformation. LA Bur- ley 21 (Legg et al., 1970) was transformed with pCK6, while the previously described (Blaszczyk et al., 1999) transgenic lines CE-20 and CEM-12 (containing alleles of E. coli cys $E$ coding for wild type and mutated SAT, respectively) were each transformed with $\mathrm{pCK} 8$. The mutated SAT that is present in CEM-12 contains $\mathrm{Met}^{256}$ substituted with Ile and is insensitive to the feedback inhibition by cysteine (Denk \& Bock, 1987; Nakamori et al., 1998). Three groups of plants transformed with $E$. coli genes, (i) $\underline{c} y s \underline{K}$ (CK), (ii) $\underline{c} y s \underline{E}$ and $c y s \underline{K}$ (CEK), (iii) $c y s \underline{E}$ mutated and $c y s \underline{K}$ (CEMK), were obtained. In fourteen plants (per 15 regenerated) from the CK group bacterial OASTL was detected, while only in one plant (per eight regenerated) from the CEK group and four plants (per 20 regenerated) from the CEMK group the Western analysis confirmed the presence of a bacterial enzyme (Fig. 1).
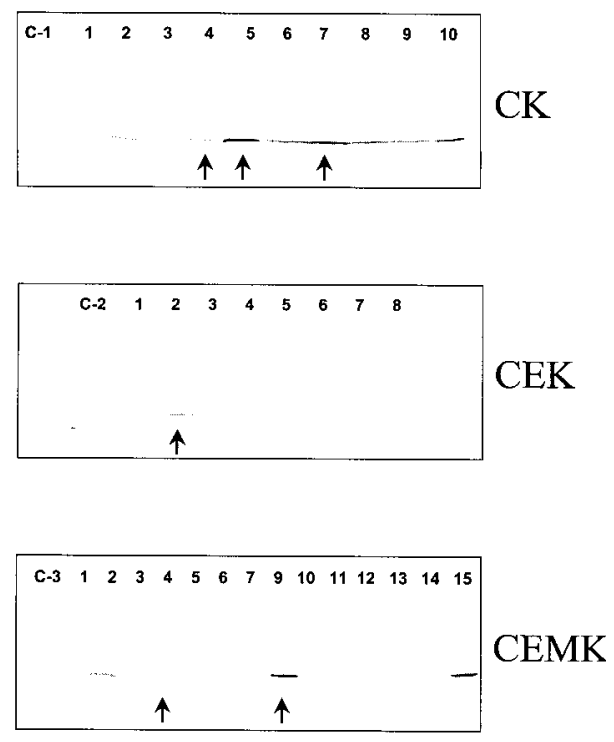

Figure 1. Western blot analysis of transgenic tobacco plants $\left(T_{0}\right.$ generation) transformed with pCK6 (CK group) and pCK8 (CEK and CEMK groups).

Rabbit anti-E. coli OAS-TL serum was used as a source of primary antibodies. The numbers denote individual plantlets regenerated upon Agrobacterium-mediated transformation. The controls C-1, C-2 and C-3 denote plant lines used for the transformation, i.e. LAB21, CE-20 and CEM-12, respectively. Arrows mark the primary transformants arbitrarily chosen for further investigations. For more information see the Results. 
Segregation of the selection markers in the $\mathrm{T}_{1}$ generation of several arbitrarily chosen primary transformants was analyzed (Table 1). It is worth to emphasize that the double pected, the transformed plants had significantly elevated OAS-TL activity in comparison to the parental lines, however, strong variation among plants from the same lines (large

Table 1. Segregation of the selection markers, kanamycin (kan) and phosphinotricin (pho), in the progeny $\left(T_{1}\right)$ of transgenic plants.

$\mathrm{R}$ - resistant, $\mathrm{S}$ - sensitive, * denotes either mutated protein or a mutated gene.

\begin{tabular}{llcccl}
\hline Plant & $\begin{array}{l}\text { Bacterial enzyme } \\
\text { overproduced }\end{array}$ & Marker & $\begin{array}{c}\text { Number of seed- } \\
\text { lings (R }: S)\end{array}$ & $\begin{array}{c}\text { Calculated } \\
\text { ratio }\end{array}$ & $\begin{array}{l}\text { Most probable num- } \\
\text { ber of inserts }\end{array}$ \\
\hline CK-4 & OAS-TL & kan & $199: 64$ & $3.1: 1$ & $1(c y s K)$ \\
CK-5 & OAS-TL & kan & $226: 81$ & $2.8: 1$ & $1(c y s K)$ \\
CK-7 & OAS-TL & kan & $219: 83$ & $2.6: 1$ & $1(c y s K)$ \\
CE-20 & SAT & kan & $181: 50$ & $3.6: 1$ & $1(c y s E)$ \\
CEK-2 & OAS-TL & pho & $161: 47$ & $3.4: 1$ & $1(c y s K)$ \\
& SAT & kan & $92: 29$ & $3.2: 1$ & Heterozygous cysE \\
CEM-12 & SAT* & kan & $102: 32$ & $3.2: 1$ & $1\left(c y s E^{*}\right)$ \\
CEMK-4 & OAS-TL & pho & $115: 28$ & $4.1: 1$ & 1 or 2 (cysK) \\
& SAT* & kan & $161: 51$ & $3.2: 1$ & Heterozygous cysE* \\
CEMK-9 & OAS-TL & pho & $72: 24$ & $3.0: 1$ & $1(c y s K)$ \\
& SAT* & kan & $240: 0$ & - & Homozygous cysE \\
\hline
\end{tabular}

transformants regenerated after transformation of CE-20 and CEM-12 with the cysK cassette had different status in regard to the cysE cassette, i.e. CEK-2 and CEMK-4 were heterozygous, while CEMK-9 was homozygous. Verification of the status (homo- or heterozygous) of the CE-20 and CEM-12 seedlings by segregation of the selection marker in the progeny was impossible prior to the transformation with pCK8. These kanamycin-resistant seedlings $\left(\mathrm{T}_{1}\right.$ generation) were germinated from the seeds of primary ( $\mathrm{T}_{0}$ generation) "unstabilized" transformants, CE-20 and CEM-12, therefore, they could be either homo- or heterozygous in regard to the cys $E$ transgene.

The selection-marker-resistant plants of the $\mathrm{T}_{1}$ generation from the primary cysK transformants (CK-4, CK-5, CK-7, CEK-2, CEMK-4, CEMK-9) and parental lines (LAB 21, CE-20 and CEM-12) were used for further experiments. The specific OAS-TL and SAT activities determined in three successive leaves collected during the early vegetative stage of plant development are shown in Fig. 2. As ex-
S.D. values) and between different leaves from the same plants was observed. SAT activities in CE-20 and CEM-12 lines were higher than in the control, mostly in the upper and the lower leaves. The double CEK and CEMK tranformants had reduced SAT activities in comparison to their parental strains (CE and CEM, respectively) in the upper and lower leaves but not in the middle ones. To prove that the observed elevated OAS-TL activities in transgenic plants correlate with the presence of bacterial OAS-TL protein, both the enzymatic assay and Western blot analysis were performed on leaf tissue material collected from the upper most developed leaves of the plants used for assays shown in Fig. 2, but grown for additional four weeks in a greenhouse. A several-fold higher OAS-TL activity than assayed in the earlier stages was detected in plants from the CK, CEK and CEMK groups (Fig. 3). A positive correlation between the presence of a protein immunodetected by rabbit anti- $E$. coli OAS-TL serum and the OAS-TL enzymatic activity was ob- 

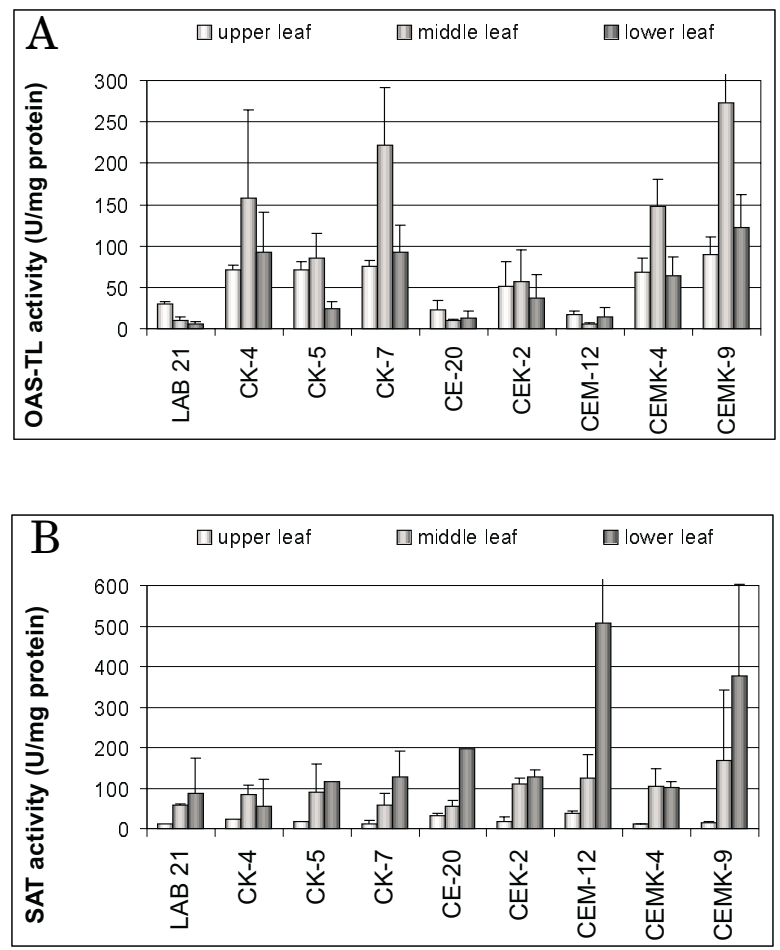

Figure 2. Specific activities of OAS-TL (Panel A) and SAT (Panel $B$ ) in individuals of $T_{1}$ generation of tobacco transformants during an early stage of plant development (rosette stage).

Leaf tissue material was collected from three successive leaves of plants grown in greenhouse conditions. Data are means \pm S.D. for two/three individuals (CK, CEK, CEMK) or of three independent assays from a single plant (LAB 21, CE-20, CEM-12). In the cases where S.D. is not indicated SAT activity was assayed only in one plant of the pertinent line. served (Fig. 3). The change of the balance between the two important enzymes involved in cysteine biosynthesis might have an impact on the level of sulfhydryl-containing metabolites (represented mainly by GSH) in the leaf tissue. In order to reveal potential differences in the level of reduced thiols two individual plants of the following groups were used in experiments described below: (i) randomly selected $\mathrm{T}_{1}$ of CK-7 and (ii) CEK-2, (iii) homozygous $\mathrm{T}_{2}$ plants of the $\mathrm{CE}-20$ line, and (iv) untransformed LAB 21 plants. Plants were grown in soil in a growth chamber for 14 weeks and leaf discs expunged from the fourth leaf from the top were assayed for the amount of reduced non-protein thiols either directly or after incubation for $45 \mathrm{~h}$ in solutions of various compounds. The experiment was performed in growth chamber conditions with the photoperiod as described in the Materials and Methods. Before incubation all transgenic plants had an elevated level of reduced thiols in the leaves as compared to the controls, however, this increase was different in the various groups of transformants (Fig. 4). Different plant groups responded differently to the feeding with the same compounds. To start with, incubation of leaf discs in distilled water resulted in an increase of the reduced non-protein thiols in all plant groups. The
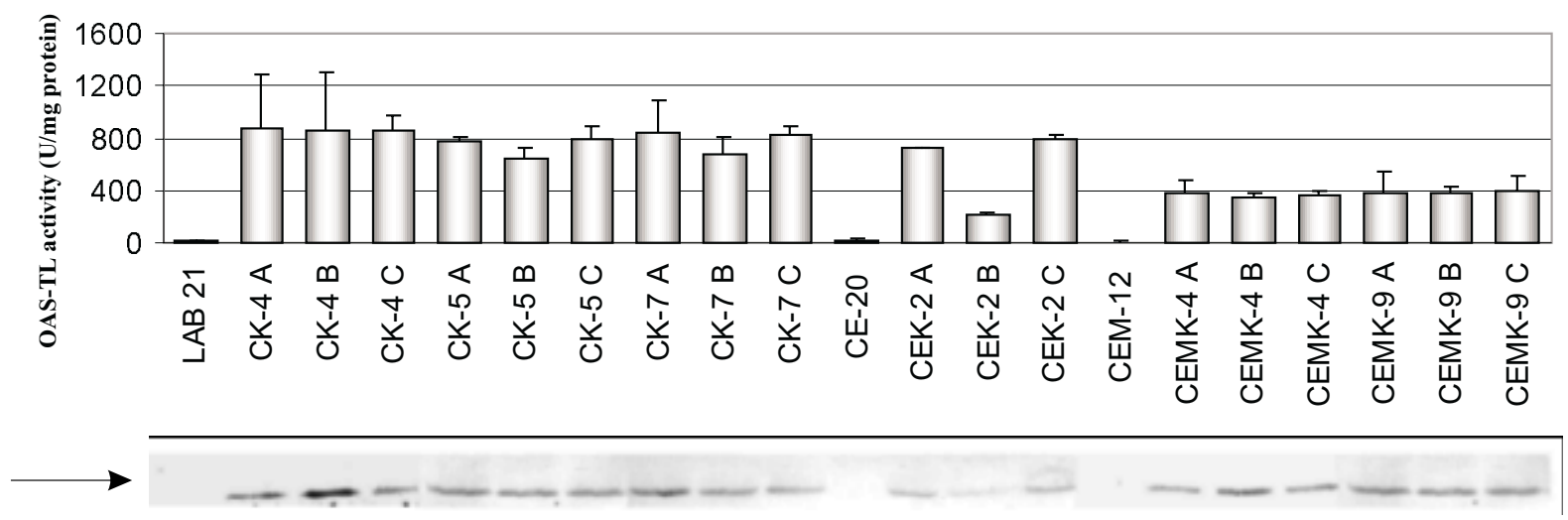

Figure 3. OAS-TL activity (upper part) and protein detected by Western blot analysis (lower part) in transgenic plants.

The arrow shows the position of the protein $(34.5 \mathrm{kDa})$ immunodetected in crude protein extract from plant leaves by rabbit anti- $E$. coli OAS-TL serum. Data shown for enzymatic activity are means \pm S.D. of three independent assays. 
largest increase was found in CE-20 (155\% of the level before incubation), CK-7 and CEK-2 showed an intermediate elevation of thiols levels ( $140 \%$ and $133 \%$, respectively), while the least rise was found in LAB 21 (120\% of the initial level). Incubation in a sulfite solution did not radically change the above effect, however, sulfate caused an over two-fold increase of the level of reduced thiols in LAB 21, CK-7 and CE-20, while only $50 \%$ increase in CEK-2, therefore, leaf discs from CE-20 plants had the highest thiols contents after incubation in sulfate. OAS caused a significant increase of reduced thiols levels in all plant lines, but, sur-

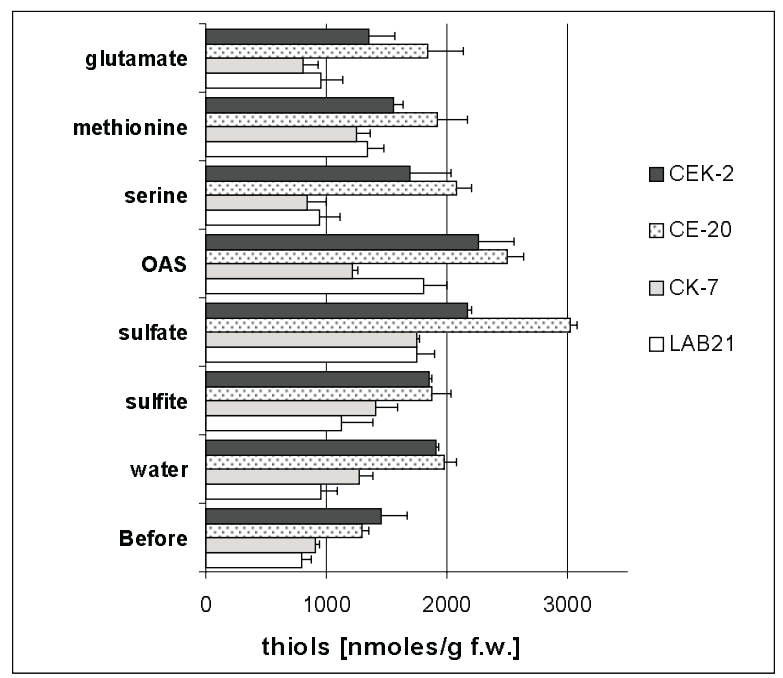

Figure 4. Effects of different compounds on the level of reduced non-protein thiols in leaf discs of analyzed plants.

Leaf discs ( $8 \mathrm{~mm}$ in diameter) were cut out from the fourth mature leaf and floated either on distilled water or on aqueous solutions of the indicated amino acids (10 $\mathrm{mM}$ each), OAS (1 mM), sulfate ( $5 \mathrm{mM})$, sulfite (1 $\mathrm{mM}$ ) for $45 \mathrm{~h}$ in the conditions of the growth chamber used for plants cultivation. Data are means \pm S.D. of six independent incubations (two plants from each group were analyzed in triplicates). f.w., fresh mass.

prisingly the increase in CK-7 plants was rather small and comparable to the elevation caused by incubation in water. Incubation in serine resulted in a low level of thiols in CK-7 plants (below the level detected in distilled $\mathrm{H}_{2} \mathrm{O}$ ), while the levels of thiols in other groups were comparable to the levels detected in water. Methionine did not influence thiols levels in either of the groups except for a slight negative effect in CEK-2. Glutamine, a direct precursor of glutathione, caused a significant reduction of thiols in all transgenics in comparison to distilled $\mathrm{H}_{2} \mathrm{O}$, however, plants containing bacterial OAS-TL were the most significantly affected; in CK-7 and CEK-2 the level of thiols detected after incubation in a glutamate solution was $80 \%$ of the initial level (before incubation).

\section{DISCUSSION}

The overproduction of bacterial SAT in transgenic tobacco plants previously created in our laboratory (Blaszczyk et al., 1999) resulted in a significant increase of cellular thiols and a resistance to oxidative stress. The presence of wheat OAS-TL in tobacco led to the resistance of the transgenic plants to the toxic levels of hydrogen sulfide due to its faster incorporation into cysteine (Youssefian et al., 1993). More detailed biochemical investigations were performed with tobacco plants overproducing spinach OAS-TL targeted to either cytosol or chloroplasts (Saito et al., 1994). The transgenic plants had only slightly increased levels of cysteine and glutathione which suggested a weak influence of the increased cellular OAS-TL activity on the in vivo production of these sulfhydryl metabolites. Upon OAS feeding of chloroplasts isolated from the tobacco containing chloroplast-targeted spinach OAS-TL the level of cysteine was significantly elevated, while GSH content was reduced (Saito et al., 1994). Similarly, in our study a selective drop of thiols in CK-7 plants (Fig. 4) upon OAS feeding was observed. The mechanisms of this effect as well as the reasons of increased thiols levels in SAT-overproducing plants upon OAS feeding remain unclear, since SAT-overproducers were supposed to have high intrinsic level of OAS. 
On the other hand, the results of in vitro experiments led to the conclusion that a large excess of OAS-TL over SAT is necessary to achieve a high capacity for cysteine biosynthesis (Droux et al., 1998). Such situation was observed in bacteria (Kredich et al., 1969) and plant cell compartments capable of independent cysteine biosynthesis (Ruffet et al., 1995). We demonstrated in this study that in the in vivo conditions overproduction of either SAT or OAS-TL in the cytosol had an influence on sulfur flow through the cysteine and glutathione biosynthesis pathways and accumulation of sulfhydryl metabolites. Thus, the regulation of sulfhydryl metabolites production must be a balance between negative (e.g. feedback inhibition by cysteine and GSH) and positive (e.g. OAS) signals. The method of thiols assay used in this work cannot distinguish between cysteine, glutathione, $\gamma$-glutamyl cysteine or other non-protein thiols. However, for the purpose of this work an assumption, supported by our unpublished results and those cited by Foyer \& Rennenberg (2000), might be made that the majority of the detected sulfhydryl groups came from glutathione. Therefore, the observation that increased OAS-TL activity only resulted in a small change of thiols concentration, while higher SAT activity caused much more significant effects, is in agreement with earlier data (Blaszczyk et al., 1999; Saito et al., 1994).

L-Cysteine synthesis is suppressed by the formation of a complex between SAT and OAS- TL and by the inhibitory effect of L-cysteine on SAT activity (Mino et al., 1999; Mino et al., 2000). It has previously been reported (Blaszczyk et al., 1999) that overproduction of mutated SAT, insensitive to feedback inhibition by cysteine, affects the biochemical properties of transgenic plants in a similar way as overproduction of wild type SAT.

In the light of the recent data about the SAT/OAS-TL complex formation and its effects on the properties and kinetics of both enzymes (Droux et al., 1998; Mino et al., 1999; Mino et al., 2000) a change of the balance be- tween these enzymatic activities was expected to affect production of sulfhydryl-containing metabolites in the analyzed tobacco plants. Although the results of these studies are difficult to be explained without a detailed analysis on a molecular level they prompted us to conclude that the most promising strategy to achieve plants with the maximal possible sulfhydryl metabolites contents is to increase SAT activity (not simultaneously SAT and OAS-TL). The results obtained in this work additionally support the postulated function of OAS as a positive factor for plant sulfur metabolism.

\section{R E F E R E N C E S}

Blaszczyk, A., Brodzik, R. \& Sirko, A. (1999) Increased resistance to oxidative stress in transgenic tobacco plants overexpressing bacterial serine acetyltransferase. Plant J. 20, 237243.

Bogdanova, N. \& Hell, R. (1997) Cysteine synthesis in plants: Protein-protein interactions of serine acetyltransferase from Arabidopsis thaliana. Plant J. 11, 251-262.

Bradford, M.M. (1976) A rapid and sensitive method for the quantitation of microgram quantities of protein utilizing the principle of protein-dye binding. Anal. Biochem. 72, 248-254.

Carrington, J.C., Freed, D.D. \& Leinicke, A.J. (1991) Bipartite signal sequence mediates nuclear translocation of the plant potyviral NIa protein. Plant Cell 3, 953-962.

Denk, D. \& Bock, A. (1987) L-Cysteine biosynthesis in Escherichia coli: Nucleotide sequence and expression of the serine acetyltransferase $(c y s E)$ gene from the wild-type and a cysteine-excreting mutant. J. Gen. Microbiol. 133, $515-525$.

Droux, M., Ruffet, M.L., Douce, R. \& Job, D. (1998) Interactions between serine acetyltransferase and $O$-acetylserine (thiol) lyase in higher plants - structural and kinetic proper- 
ties of the free and bound enzymes. Eur. J. Biochem. 255, 235-245.

Firoozabady, E. \& Kuehnle, A.R. (1995) Agrobacterium-mediated transformation; in Plant Cell, Tissue and Organ Culture. Fundamental Methods (Gamborg, O.L. \& Phillips, G.C., eds.) pp. 181-195, Springer-Verlag, Berlin.

Foyer, C.H. \& Rennenberg, H. (2000) Regulation of glutathione synthesis and its role in abiotic and biotic stress defence; in Sulfur Nutrition and Sulfur Assimilation in Higher Plants (Brunold, C., Rennenberg, H., De Kok, L.J., Stulen, I. \& Davidian, J.-C., eds.) pp. 127-153, Paul Haupt, Bern.

Hellens, R.P., Edwards, E.A., Leyland, N.R., Bean, S. \& Mullineaux, P.M. (2000) pGreen: A versatile and flexible binary Ti vector for Agrobacterium-mediated plant transformation. Plant Mol. Biol. 42, 819-832.

Inoue, K., Noji, M. \& Saito, K. (1999) Determination of the sites required for the allosteric inhibition of serine acetyltransferase by L-cysteine in plants. Eur. J. Biochem. 266, 220-227.

Jagura-Burdzy, G. \& Hulanicka, D. (1981) Use of gene fusions to study expression of cysB, the regulatory gene of the cysteine regulon. $J$. Bacteriol. 147, 744-751.

Kredich, N.M., Becker, M.A. \& Tomkins, G.M. (1969) Purification and characterization of cysteine synthetase, a bifunctional protein complex from Salmonella typhimurium. J. Biol. Chem. 244, 2428-2439.

Kredich, N.M. \& Tomkins, G.M. (1966) The enzymic synthesis of L-cysteine in Escherichia coli and Salmonella typhimurium. J. Biol. Chem. 241, 4955-4965.

Legg, P.D., Collins, G.B. \& Litton, C.C. (1970) Registration of LA Burley 21 tobacco germplasm. Crop Sci. 10, 212.

Mino, K., Yamanoue, T., Sakiyama, T., Eisaki, N., Matsuyama, A. \& Nakanishi, K. (1999) Purification and characterization of serine acetyltransferase from Escherichia coli partially truncated at the C-terminal region. Biosci. Biotech. Biochem. 63, 168-179.

Mino, K., Yamanoue, T., Sakiyama, T., Eisaki, N., Matsuyama, A. \& Nakanishi, K. (2000) Effects of bienzyme complex formation of cysteine synthetase from Escherichia coli on some properties and kinetics. Biosci. Biotech. Biochem. 64, 1628-1640.

Murashige, T. \& Skoog, F. (1962) A revised medium for rapid growth and bio assays with tobacco tissue cultures. Physiol. Plant. 15, 473-493.

Nakamori, S., Kobayashi, S.I., Kobayashi, C. \& Takagi, H. (1998) Overproduction of L-cysteine and L-cystine by Escherichia coli strains with a genetically altered serine acetyltransferase. Appl. Env. Microbiol. 64, 1607-1611.

Nakamura, T., Yamaguchi, Y. \& Sano, H. (1999) Four rice genes encoding cysteine synthase: Isolation and differential responses to sulfur, nitrogen and light. Gene 229, 155-161.

Noctor, G., Arisi, A.C.M., Jouanin, L., Kunert, K.J., Rennenberg, H. \& Foyer, C.H. (1998) Glutathione: Biosynthesis, metabolism and relationship to stress tolerance explored in transgenic plants. J. Exp. Bot. 49, 623-647.

Noji, M., Inoue, K., Kimura, N., Gouda, A. \& Saito, K. (1998) Isoform-dependent differences in feedback regulation and subcellular localization of serine acetyltransferase involved in cysteine biosynthesis from Arabidopsis thaliana. J. Biol. Chem. 273, 32739-32745.

Rossi, L., Escudero, J., Hohn, B. \& Tinland, B. (1993) Efficient and sensitive assay for T-DNA-dependent transient gene expression. Plant Mol. Biol. Rep. 11, 220-229.

Ruffet, M.L., Lebrun, M., Droux, M. \& Douce, R. (1995) Subcellular distribution of serine acetyltransferase from Pisum sativum and characterization of an Arabidopsis thaliana putative cytosolic isoform. Eur. J. Biochem. 227, 500-509.

Saito, K. (2000) Regulation of sulfate transport and synthesis of sulfur-containing amino acids. Curr. Opin. Plant Biol. 3, 188-195.

Saito, K., Kurosawa, M., Tatsuguchi, K., Takagi, Y. \& Murakoshi, I. (1994) Modulation of cysteine biosynthesis in chloroplasts of transgenic tobacco overexpressing cysteine synthase [O-acetylserine(thiol)-lyase]. Plant Physiol. 106, 887-895. 
Sambrook, J., Fritsch, E.F. \& Maniatis, T. (1989) Molecular Cloning. A Laboratory Manual. 2nd Edn., Cold Spring Harbor Laboratory Press, Cold Spring Harbor.

Takahashi, H., Yamazaki, M., Sasakura, N., Watanabe, A., Leustek, T., Engler, J.A., Engler, G., Van Montagu, M. \& Saito, K. (1997) Regulation of sulfur assimilation in higher plants: a sulfate transporter induced in sulfate-starved roots plays a central role in Arabidopsis thaliana. Proc. Natl. Acad. Sci. U.S.A. 94, 11102-11107.

Warrilow, A.G.S. \& Hawkesford, M.J. (1998) Separation, subcellular location and influence of sulphur nutrition on isoforms of cysteine synthase in spinach. J. Exp. Bot. 49, 1625-1636.

Yanisch-Perron, C., Vieira, J. \& Messing, J. (1985) Improved M13 phage cloning vectors and host strains: Nucleotide sequences of the M13mp18 and pUC19 vectors. Gene 33, 103-119.

Youssefian, S., Nakamura, M. \& Sano, H. (1993) Tobacco plants transformed with the $O$-acetylserine (thiol) lyase gene of wheat are resistant to toxic levels of hydrogen sulphide gas. Plant J. 4, 759-769. 